\title{
NARRATIVAS MUSICAIS CONTEMPORÂNEAS ENTRE O LOCAL E O GLOBAL: OS CASOS DO FUNK BRASILEIRO E DO KUDURO ANGOLANO
}

\author{
Debora Costa de Faria ${ }^{1}$ \\ Universidade Federal de São Paulo, Guarulhos, Brasil
}

\begin{abstract}
Este artigo tem como objetivo entender a trajetória de dois gêneros musicais, o funk brasileiro e o kuduro angolano. Apesar das diferentes configuraçôes históricas nas quais se inserem, funk e kuduro têm algumas semelhanças. São criados, sobretudo, por jovens moradores de zonas marginalizadas de grandes cidades, mas, apesar dos preconceitos e dificuldades que enfrentam, estão conectados com o mundo, especialmente a partir dos fluxos globais de pessoas, sons e imagens. Esses jovens são empoderados pelo barateamento e a maior acessibilidade a artefatos tecnológicos. E por essa razão, desafiam lógicas e dinâmicas da indústria da cultura e do entretenimento ao criar suas próprias narrativas e identidades por meio da produção de canções, expressões corporais e imagens. Deste modo, contestam o papel conferido a eles de simples receptores para se tornarem protagonistas e agentes nas e das localidades onde vivem, estabelecendo, assim, novas geografias de produção, edição e consumo de música.

Palavras-chave: funk brasileiro, kuduro angolano, música, dança
\end{abstract}

\section{INTRODUÇÃO}

A valorização de uma estética cultural entendida como "periférica" tem sido revelada e intensificada ao longo dos últimos anos, ressignificando o termo geralmente atrelado a lugares repletos de carências, ausências e fortemente afetados por processos de precarização ${ }^{2}$.

1 Uma versão inicial deste artigo foi apresentada na 30a Reunião Brasileira de Antropologia, realizada entre os dias 03 e 06 de agosto de 2016, João Pessoa/PB. Contato da autora: faria.debc@gmail.com.

2 O termo periferia(s), assim como os espaços apontados como tais, são bastante polissêmicos e heterogêneos. Neste artigo refiro-me às regiões da cidade que (estejam elas situadas em seu centro ou distante dele) são majoritariamente ocupadas pelas populações mais pobres da sociedade e, fortemente marcadas, nas mais diversas esferas, por processos excludentes e de precarização. Breves apontamentos sobre os possíveis significados e im- 
Pesquisadores e artistas de variadas vertentes, ativistas, produtores locais e estrangeiros, apreciadores e até mesmo o poder público e a iniciativa privada são partes fundamentais desse movimento que começa a compreender as periferias para além das costumeiras oposições ao centro e a reconhecê-las por sua criatividade e especificidade.

Na música, o funk brasileiro e o kuduro angolano são bons exemplos desse fenômeno. Frutos de articulações referidas às sonoridades locais e globais, esses dois gêneros de música e dança têm se consolidado como duas importantes manifestações culturais contemporâneas em seus respectivos países e, em certa medida, também fora deles.

O funk no Brasil e o kuduro em Angola são tomados, sobretudo, por jovens pertencentes às camadas mais pobres da população, moradores de áreas inseridas em grandes centros urbanos e desassistidas pelo Estado. E, embora possam enfrentar dificuldades, essas moças e (majoritariamente) rapazes estão conectados com o mundo e são empoderados pelo barateamento, avanço e o maior acesso a artefatos tecnológicos, sejam eles computadores, softwares, equipamentos de som e vídeo ou celulares. Estimulados por isso, tomam para si tais inovações e contestam as lógicas e dinâmicas das indústrias tradicionais de cultura e entretenimento ao criar suas próprias narrativas e formas de enunciação. Por meio da produção de canções, expressões corporais e imagens deixam de ser apenas receptores passivos para se tornarem protagonistas e agentes nas e das localidades onde vivem, estabelecendo, então, modos alternativos de formação de identidade, bem como novos espaços de produção, circulação e consumo. Ou ainda, como indicam Aderaldo e Raposo (2016: 288), "reelaboram o significado de ser jovem (pobre e negro), formulando identidades positivas sobre si próprios que desafiam as visões hegemônicas de seu lugar social."

Este artigo é uma versão atualizada e modificada da dissertação de mestrado "O local e o global no funk brasileiro e no kuduro angolano". Respeitando suas particularidades, o objetivo da pesquisa, realizada entre 2012 e 2014, era encontrar similitudes entre os dois gêneros que, embora geograficamente separados, fazem parte de um contexto no qual pessoas espacialmente e socialmente marginalizadas, entrelaçam, a despeito dos poucos recursos que possuem e dos estigmas a elas relacionados, culturas locais e globais, criatividade, representatividade e se mostram para o mundo especialmente a partir do uso da tecnologia. Nesse processo foram utilizadas diversas fontes, e, além da revisão bibliográfica, o uso da internet foi fundamental para o desenvolvimento da pesquisa. Nela, assim como neste artigo, foram também imprescindíveis as informações obtidas a partir da utilização de materiais audiovisuais disponíveis em plataformas como Youtube, programas de televisão angolanos transmitidos em streaming (pela Televisão Pública Angolana, a TPA Internacional) e filmes relacionados aos dois gêneros, entre eles está o I love kuduro de Mário Patrocínio que teve sua estreia no Festival do Rio, em 2013. Além disso, entrevistas e conversas informais com artistas, produtores, DJs e especialistas nos gêneros também foram importantes, assim como incursões a eventos relacionados ao funk e ao kuduro. Entre eles estão palestras e seminários como a Conferência Internacional sobre o Kuduro em Angola e a apresentação do documentário Off the beaten track, em Lisboa, cidade onde, assim

plicações do termo podem ser encontradas na apresentação de 2012 do evento Estéticas das periferias, disponível em: https://www.sescsp.org.br/online/artigo/6570_ESTETICAS+DA+PERIFERIA e no debate proposto pela revista Continuum a pesquisadores de diversas áreas e disponível em: https://issuu.com/itaucultural/docs/continium_junho-julho. No caso de expressões artísticas, e, mais precisamente da música, refiro-me também a artistas que produzem seus trabalhos sem o apoio ou à margem da grande mídia e/ou das indústrias fonográficas e do entretenimento estabelecidas. 
como em São Paulo, foram feitas observações em casas noturnas e assistidas apresentações de artistas dos dois gêneros.

\section{Do FUNK CARIOCA AO FUNK BRASILEIRO}

Que o Helipa, é baile de favela/ Que a Marconi é baile de favela/ E a São Rafael é baile de favela ${ }^{3}$

Embora não seja um gênero "tipicamente" brasileiro, o funk tem se constituído, pelo menos desde os anos de 1970, como uma das manifestações culturais mais importantes entre a juventude das classes populares do país. Gerado a partir de fusões e misturas e ressignificado desde o momento em que adentrou terras brasileiras, o funk foi tornando-se carioca a partir da iniciativa e dos anseios de produtores, DJs, radialistas e amantes da música - entre eles, Big Boy e Ademir Lemos -, interessados em trazer as vibrações do gênero norte-americano para os clubes e festas que aconteciam primeiramente na zona Sul e, mais tarde, nos subúrbios do Grande Rio de Janeiro. Tal estabelecimento foi acentuado com o surgimento dos Bailes da Pesada e dos Bailes Black em um movimento no qual foram criadas também as equipes de som responsáveis por sua produção (Vianna 1987, Essinger 2005, Sá 2007).

Naquela época, a trilha sonora daqueles eventos incluía, além do próprio funk (cujo grande representante era James Brown), o soul e, mais tarde, o hip hop e o miami bass. Este último, resultado da mistura acidental feita por Afrika Baambata entre o rap e a música eletrônica do Kraftwerk, acabou por converter-se na base formadora daquilo que posteriormente se tornaria o funk carioca (Vianna 1987, Essinger 2005, Sá 2007).

Toda essa musicalidade norte-americana foi, sem demora, reinterpretada pelos frequentadores dos bailes que ouviam as músicas estrangeiras e davam a elas novos sentidos. Ao impor situações cotidianas e retratar sensibilidades locais baseando-se na sonoridade das músicas em inglês, que pouco ou mal entendiam, eles inventavam refrãos e versões popularmente conhecidas como melôs (Vianna 1987, Herschmann 2000, Sá 2007, Assef 2008). Porém, é no final dos anos 1980 que as batidas começam a ser nacionalmente produzidas. Em 1989 é lançado Funk Brasil, o primeiro disco dedicado ao gênero e concebido a partir das experimentações de DJ Marlboro. Apesar de ser uma das figuras mais conhecidas e controversas de uma história do funk no Brasil, Marlboro não é o único a destacar-se nesse período que ainda conta com atuação de outros produtores como Grandmaster Raphael, responsável, naquele mesmo ano, pelo álbum Super quente (Essinger 2005).

Embora no Brasil o funk "carioca" tenha se tornado um dos mais populares, é possível notar que desde essa época tem havido um processo de espraiamento, já que há anos o gênero e as práticas articuladas a ele não se restringem apenas ao Rio de Janeiro. A percepção dessa fluidez indica que ele possa ser chamado de brasileiro, mas isso não significa que ele tenha sido adotado de forma singular e estática ao longo dos anos, pelo contrário. Seu dinamismo é demonstrado pelas peculiaridades que ganha à medida que é nacionalmente difundido e apropriado.

3 Trecho da música "Baile de Favela” (2016) de MC João. 
Com criatividade, os funkeiros integraram às questões cotidianas e da comunidade sonoridades afro-brasileiras e samples de diversas origens (Sá 2007). Assuntos polêmicos como a sexualidade e apologia ao crime também foram acrescidos às letras. $\mathrm{O}$ mesmo acontece com temáticas como o empoderamento feminino e o consumo de marcas famosas. Hoje multifacetado, o funk conta com diversas vertentes: sensual, proibidão, romântico, ostentação e gospel são algumas delas. Além disso, ele incorpora e tem incorporado outros gêneros musicais como pagode, sertanejo e MPB. Por essas razões, é possível sustentar que as batidas do funk são ouvidas, dançadas e produzidas por todo o país. Movimento que confirma, portanto, a habilidade de seus produtores e admiradores de (re)combinar de forma engenhosa temas e sonoridades. A título de exemplo, essas fusões acontecem em trabalhos de artistas tão diversos como Gal Costa e sua música "Miami Maculelê" (2011) e em sucessos como "Eu quero tchu, eu quero tcha" (2012), da dupla sertaneja João Lucas \& Marcelo e "Você partiu meu coração" (2017) parceria de Nego do Borel, Anitta e Wesley Safadão.

O funk produzido no Brasil, o imaginário e a imagética associados a ele, têm sido gradativamente absorvidos pelos meios de comunicação, programas populares de televisão e peças publicitárias de grandes marcas. Nesse sentido, é destaque, ainda, o uso cada vez mais comum desse gênero em trilhas sonoras de filmes como Tropa de Elite (2007) e telenovelas como A força do querer (2017). Geralmente, isso ocorre com o intuito de recriar a atmosfera e o cotidiano das comunidades pobres e de seus moradores, crescentemente retratados nesses produtos audiovisuais (Silva 2014). Similarmente, outras iniciativas têm agregado funkeiros e suas práticas. Este é o caso dos programas Bagulho louco (2016), apresentado por Mr. Catra no canal Multishow e Lucky Ladies (2015), reality show comandado por Tati Quebra Barraco, exibido pela Fox Life e cujo objetivo era formar ídolos femininos do gênero. Tais fatos assinalam a popularidade, dinamismo e versatilidade do funk, sua viabilidade mercadológica, além da possibilidade de suas batidas e artistas conquistarem e ocuparem diversos espaços.

O funk tem mostrado ser viável enquanto produto, ${ }^{4}$ gerando renda para centenas de pessoas, começando a ser entendido como trabalho e tornando-se investimento familiar, como aconteceu com a carreira de MC Gui, incentivada desde cedo pelos pais. E em tempos nos quais a quantidade de visualizações e "curtidas" na internet são valorizadas, podendo ser convertidas em rendimentos e tirar jovens do anonimato, Conrad Dantas se destaca. Um dos maiores produtores de vídeo do gênero (inicialmente de sua versão "ostentação", um tipo de funk, assim como ele, proveniente da Baixada Santista), Kondzilla, como é conhecido, foi um dos primeiros a perceber que existia neste meio um mercado inexplorado para a produção audiovisual. Isso considerado, e ciente da carência de representatividade por parte dos criadores e do público de funk, concebeu em seus trabalhos uma estética inspirada pelos clipes de hip hop norte-americanos que, assim como os funkeiros de São Paulo, ostentam e valorizam na mesma medida carros, roupas de grife, joias e mulheres. Deste modo, valendo-se da popularização dos meios digitais e perspicaz quanto à potência da visualidade no contexto atual, deu amplitude ao gênero e às imagens produzidas a partir dele. A empreitada iniciada com vídeos que já foram vistos mais de 10 bilhões de vezes no Youtube agrega também uma produtora de shows, gravadora e uma série de produtos de marca própria, incluindo peças de vestuário e acessórios. Tais conquistas

4 Uma das pesquisas mais importantes sobre o assunto, Configurações do mercado funk no Rio de Janeiro, foi feita pela Fundação Getúlio Vargas em 2008. 
tornaram Kondzilla (e sua marca) um dos nomes mais notórios no mercado de música e de produção de imagens no Brasil. ${ }^{5}$

Apesar do notável sucesso, que muitas vezes ultrapassa as barreiras das classes sociais, ${ }^{6} \mathrm{o}$ gênero e aqueles que se dedicam a ele experimentam uma dupla e ambivalente condição. Se por um lado, como apontam Herschmann e Freire Filho (2003) vivenciam uma espécie de "glamourização" no momento em que seus aspectos identitários, culturais e estilos de vida são positivamente valorados, por outro, ainda sofrem com constantes tentativas de criminalização e com o preconceito. Essa situação torna o funk produzido no país, seus adeptos e admiradores, desafios para o Estado e alguns setores da sociedade brasileira que em diversos contextos demonstram ser incapazes de lidar com o gênero para além das esferas do crime ou da moralidade.

Para entender como isso acontece, é comum remontar a um episódio cuja influência parece ter sido fundamental para estabelecer os marcos desfavoráveis com os quais o gênero e seus praticantes têm sido estigmatizados ao longo dos anos. Ocorrida em 1992, a movimentação em massa de jovens - em sua maioria negros e vindos dos subúrbios e favelas -, pelas praias da zona Sul da cidade do Rio de Janeiro causou repercussões negativas e ajudou a instaurar um clima de insegurança entre os habituais frequentadores da região (Herschmann 2000; Essinger 2005; Sá 2007). A ampla difusão das imagens e as narrações em torno delas pelos meios de comunicação colaboraram para essa situação e sustentaram a criação de um imaginário sonoro e imagético que deram visibilidade ao funkeiro enquanto uma figura nociva e perigosa (Arruda et al. 2010; Silva 2016).

Como já observado anteriormente na dissertação, isso se efetuou de tal modo que, embora o "arrastão" - como ficou conhecido o incidente -, tenha acontecido há mais de 20 anos, até hoje o evento suscita discussões em torno da associação generalizada entre (mau) gosto musical, cor da pele, pobreza e local de moradia, marginalidade, criminalidade e juventude, centro, periferia, mobilidade e direito ao uso dos espaços (públicos) urbanos. Discussões que reverberam em momentos nos quais a sociedade, o poder público e os meios de comunicação deparam-se com fenômenos como os "rolezinhos" 7 e os pancadões de rua, (ou "fluxos"), ambos ocorridos nos últimos anos na cidade de São Paulo. O primeiro ocupou os noticiários brasileiros entre o final 2013 e os primeiros meses de 2014 e foi caracterizado pelos encontros marcados via redes sociais entre jovens que, ao som do funk, lotavam os shoppings da cidade. Por serem considerados ameaças, aquelas moças e rapazes preocuparam os lojistas que conseguiram intervir judicialmente na situação de modo a coibir, não raro de forma violenta, essas manifestações. $\mathrm{O}$ mesmo tem acontecido com os fluxos, tornando-se alvos de reclamações da população, denúncias dos meios de comunicação e ações truculentas por parte da polícia, chamada para reprimir as festas de rua acompanhadas pelo som alto saído dos equipamentos acoplados aos carros. Nos dois casos, o poder público empreendeu esforços para regular tais expressões sugerindo espaços

\footnotetext{
5 Para mais informações consultar: http://www.kondzilla.com/ e https://www.youtube.com/ watch?v=KSxoqda1a9A

6 Conforme apontou Essinger (2005), ao longo dos anos alguns funkeiros vêm se apresentando em clubes e casas noturnas consideradas de classe média e por outro lado, pelo menos desde meados dos anos de 1990, alguns dos jovens pertencentes a essa camada social têm frequentado os bailes de comunidade.

7 Para mais análises desse fenômeno consultar: "Rolezinho no shopping: aproximação etnográfica e política" (2014), de Alexandre Barbosa Pereira e "Rolezinhos: sociabilidades juvenis, discriminações e segregação urbana" (2014), de José Gomes da Silva e Darlene Fróes da Silva.
} 
alternativos onde os eventos poderiam acontecer, ou, ainda, estabelecendo mecanismos legislativos com o intuito de inibir a música alta.

Apesar das proibições, festas como essas são correntes em alguns bairros da periferia de São Paulo e vão se estabelecendo como importantes espaços de sociabilidade e divertimento, assim como uma das principais formas de entretenimento entre os jovens frequentadores. Tais festas favorecem uma intensa circulação urbana, valoram positivamente e colocam em evidência bairros que de outra forma chamariam atenção apenas por aspectos negativos, a partir de uma perspectiva da falta (de infraestrutura, segurança e cultura). Em regiões, em muitos casos, carentes de equipamentos públicos de lazer, algumas delas marcadas por altos índices de mortalidade juvenil (especialmente de homens negros), são criados espaços de agência, novas cartografias de diversão desconhecidas pela maioria dos habitantes da cidade e dificilmente circunscritas em seus guias oficiais. Ao escolher os nomes artísticos que identificam os lugares onde vivem e cantar canções que destacam o circuito de festas da cidade, criar suas próprias sonoridades e imagens, produzir seus próprios eventos, ou movimentar seus corpos e gerar novas formas de dança, como no passinho, no passinho do Romano ou na sarrada, esses jovens ajudam a tornar visíveis não somente a efervescência cultural dos bairros onde moram e transitam, mas revelam outras formas de vivência, revelam sua própria existência.

Limites também vêm sendo impostos aos bailes funk em cidades como o Rio de Janeiro (Herschmann 2000, Herschmann e Freire Filho 2003), onde há alguns anos tem-se tentado criar ações visando seu impedimento (pelo menos nas comunidades mais pobres). Esse processo, ressaltado e tensionado pela implementação das UPPs (Unidades de Polícia Pacificadora) nas favelas e comunidades cariocas (Silva 2014,2016) não é uma novidade e está em consonância com as ressalvas sofridas pelo gênero desde sua emergência no país. De maneira geral, tais objeções tendem a ignorar as inovações do funk para caracterizá-lo como uma manifestação musical irrelevante, considerando-o uma música (de) pobre, por um lado e, a entendê-lo como um problema, por outro. Essa desconfiança em relação ao gênero gira em torno de diversas esferas, a começar por sua nominação, no momento em que é comparado e desqualificado em relação ao funk norte-americano; passando pelo conteúdo das letras, depreciadas quando contrapostas à politização do rap e chegando à crítica ao movimento erotizado dos corpos, além da associação presumida do gênero com a criminalidade.

Conforme aponta Luciane Soares da Silva (2014), não são raras as comparações entre o samba e o funk, duas manifestações populares oriundas das camadas socialmente desfavorecidas, estreitamente relacionadas a matrizes africanas e perseguidas no momento de sua geração. Não obstante essas semelhanças, a pesquisadora observa que diferente do samba, hoje considerado um dos símbolos da identidade brasileira, o funk, pela "ingovernabilidade" (de alguns) de seus elementos e práticas teria dificuldades em ascender a essa mesma condição. No entanto, nos últimos anos, as narrativas musicais com forte apelo ao consumo de marcas famosas e importadas promovidas pelo funk "ostentação" foram comuns e permitiram que o gênero alcançasse os meios de comunicação. Essa inserção tem acontecido pelo menos desde os anos de 1990, com artistas como Claudinho e Buchecha, porém, ganha um novo fôlego na segunda década dos anos 2000 com figuras como MC Guimê. Sem contar os músicos de outras vertentes do gênero, como Nego do Borel e Ludmilla que, com suas músicas mais "leves", também têm conquistado importantes espaços de exposição e divulgação. Isso seria possível devido ao afastamento das letras de músicas de artistas como esses em relação a conteúdos polêmicos, permitindo, assim, 
que versões mais suaves do gênero sejam encaradas como uma espécie de "funk do bem" (Pereira 2014), e deste modo, tornando-se mais palatáveis a um público mais amplo.

Essa maior facilidade de circulação, porém, não isentou o funk ostentação de críticas, pois o conteúdo das letras engendra questionamentos sobre a autenticidade de músicas e imagens construídas em torno do consumo, mas cantadas e representadas por jovens, em sua maioria, pobres. Essas críticas desconsideram o papel da criatividade e da imaginação nas composições das músicas, dos vídeos e das identidades, ao enfatizar ou pretender que a um grupo social seria permitido retratar apenas experiências baseadas em vivências reais. Diferente disso, o funk ostentação, a imagética, a estética e os discursos construídos em torno dele demonstram que as afinidades e conexões podem se assentar para além dos limites do bairro, da cidade e do país, numa articulação fluida entre o local, o global e o imaginário. Isso, sobretudo, em um contexto no qual o papel dos meios de comunicação e das tecnologias de informação ganham uma relevância incontestável (Appadurai 1996; Pereira 2014).

Em um mundo de certa forma ordenado pelo consumo, com oportunidades escassas e no qual a música parece ser umas das únicas formas de ascensão e inserção social - ainda que através da aquisição de bens -, MC Guimê, um dos maiores expoentes da vertente pondera:

\begin{abstract}
Antes de nos criticarem, eles têm que criticar o canal de TV e todas as propagandas porque nós crescemos vendo isso, e como posso negar que sempre quis ter um bom carro, se cresci vendo que aquelas pessoas respeitadas na sociedade têm bons carros? [E continua] Todo dia na TV, a família rica está feliz e a família pobre está triste. Como eu não vou querer o que a eles é permitido ter? ${ }^{8}$
\end{abstract}

Como pode ser notado, são várias as controvérsias que envolvem o funk brasileiro, como estigma e preconceito, repressão, relação conflituosa com o Estado e parte da sociedade civil, além de vínculos ambíguos com os meios de comunicação e a indústria da cultura e do entretenimento. Ainda assim são percebidos pelo menos três modos possíveis de circulação e valorização do funk para além das comunidades onde é criado. O primeiro é o dos funkeiros como Tati Quebra Barraco e Deise Tigrona que, com suas performances, circularam e alcançaram o "asfalto", as pistas de dança da classe média e do mundo. O segundo, aquele no qual o funk brasileiro conquista admiradores de gêneros consagrados pela crítica especializada como Gilberto Gil e Caetano Veloso. Este último reconheceu " $[\mathrm{n}]_{\mathrm{o}}$ funk, [n]o sertanejo universitário e [n]os restos da axé music uma Tropicália ainda inexplorada”. Nesse caso, importa ressaltar que apesar da popularidade e do entusiasmo de Caetano, esses gêneros estão longe da representatividade e do atrelamento à cultura nacional investidos no samba, na bossa-nova e da própria MPB. Finalmente, o último seria aquele no qual a música ultrapassa os espaços das comunidades, do estado do Rio de Janeiro e do Brasil, passando a ser apreciado e produzido pela classe média brasileira, por produtores e DJs internacionais.

Nesse contexto de usos e apropriações do gênero, é necessário indicar os distintos graus de relação de artistas e público com o funk, pois há diferenças nos propósitos e na legitimidade

8 O trecho citado foi traduzido do inglês. A reportagem "In Brazil, music for the flaunters and the wanters", foi publicada na versão online do jornal Los Angeles Times no dia 04/04/2014 e está disponível em: http:// www.latimes.com/world/mexico-americas/la-fg-c1-ff-brazil-bling-rap-20140404-m-story.html. Último acesso: 19/06/2016.

9 Entrevista publicada pela BBC Brasil em 04 de maio de 2016 e está disponível em: http://www.bbc.com/ portuguese/noticias/2016/05/160407_caetano_mv. Acesso em: 19/06/2016. 
daqueles que usam suas batidas como referência, valorização e aproximação com o periférico e os músicos que buscam nele um projeto profissional, um estilo de vida.

\title{
Do KUDURO ANGolano
}

\author{
Kuduro é Cabinda e Cunenel Kuduro é Luanda, é Angolal \\ Kuduro é a poeira do povol É deslocado pedindo esmolal Kuduro \\ é solo que pisamos/ Kuduro é o ar que a gente respira ${ }^{10}$
}

Em alguns aspectos o kuduro em Angola parece ocupar uma posição mais confortável que o funk no Brasil e até exercer um papel privilegiado, ao menos no que se refere ao entendimento de parcelas da sociedade e do governo, de que possa se tornar símbolo de uma nação vibrante e contemporânea. Uma nação que a despeito das contínuas desigualdades, alcançou, nos últimos anos, um significativo desenvolvimento. Tal prosperidade - ainda que desigual e restrita a alguns setores da população -, está, de certa forma, relacionada à necessidade de criar novas representações de uma Angola que, embora possua recursos minerais de alto valor (petróleo e diamantes), continua conhecida pelas imagens de um país pobre e fortemente afetado pela guerra (Alisch \& Siegert 2011, Tomás 2013, Moorman s.d.).

O kuduro ganha destaque nessa conjuntura. Emerge nos anos de 1990 em um país marcado pelo sofrimento e ganha contornos extramusicais ao começar a ser percebido como forma de manutenção da ordem política (Tomás 2013), ou ainda, um meio privilegiado para corporificação dos traumas vivenciados ( Alisch \& Siegert 2013, Moorman s.d.). Nesse sentido, não é raro que o surgimento do kuduro confunda-se com as histórias e as narrativas de um país que, recém-emancipado do domínio português, conhece as agruras de uma guerra civil. $\mathrm{Na}$ recente história angolana, as lutas pela independência travadas a partir do início da década de 1960 foram prontamente substituídas, em 1975, por conflitos motivados pela disputa de sua condução - e, adicionalmente, embalados pelos desdobramentos da Guerra Fria. Duas eram as principais forças em disputa e, ainda hoje, ambas constituem os maiores partidos do país: o MPLA (Movimento Popular de Libertação de Angola), no poder desde 1975, e a Unita (União Nacional para a Independência Total de Angola). Após a liberação em relação a Portugal, as hostilidades entre as duas partes foram mantidas com breves intervalos até 2002, quando foi assinado um acordo que, oficialmente, pôs fim à guerra e anistiou todos os envolvidos nela (Alisch \& Siegert 2011, Moorman s.d.).

Os sucessivos períodos de disputa afetaram o povo angolano, sua sociedade, economia e inviabilizaram sua infraestrutura, acentuando desigualdades e carências em setores como saúde, educação, habitação e saneamento básico. Dificuldades não superadas e que permanecem a despeito do crescimento econômico alcançado pelo país no início da década (Alisch \& Siegert 2011, Moorman s.d.). O kuduro, uma das mais instigantes manifestações culturais, artísticas e estéticas dos últimos anos naquele país é comumente relacionado, por seus produtores e pesquisadores, a esse contexto de contrariedades políticas, econômicas e sociais no qual os deslocamentos em busca de refúgio poderiam figurar como a solução possível em meio aos

10 Trecho da vinheta de abertura do programa televisivo, Kuduro Vivo (Petrangol). 
dissabores vivenciados (Moorman s.d. 2014, Sheridan 2013). Essas movimentações, essenciais para a constituição do gênero de música e dança angolanas, deram-se em, pelo menos, duas direções. Em uma delas, a classe média do país encontra na mudança para a Europa, em especial Portugal, a possibilidade de escapar das contendas e do recrutamento forçado, além de encontrar emprego e melhor educação para seus filhos. Nesses novos espaços, aqueles jovens começam a ter contato com a tecnologia de produção musical da época e também com a música eletrônica, principalmente techno e house, influências importantes na tentativa de unir e mesclar referências e sons provenientes de Angola. Músicas dançadas em pares como o semba e a kizomba (Moorman s.d.), além das músicas de carnaval, são algumas delas. Nos clubes noturnos do centro de Luanda, essas misturas e as "batidas" (expressão que se refere à música eletrônica de maneira mais generalizada) serão fundamentais para o que mais tarde será conhecido como kuduro. $\mathrm{Na}$ outra frente de movimentações, a interna, a população das zonas rurais e do interior, fugindo do infortúnio e buscando melhores condições de vida, desloca-se em direção à capital do país, lugar menos atingido pelos conflitos (Moorman s.d., Sheridan 2013, Alisch \& Siegert 2013). Em Luanda, notadamente nos bairros precarizados de seu entorno, os musseques, essa população vai encontrar abrigo, mas não apenas isso, pois é a esses lugares - reconhecidos por sua grande efervescência cultural (Moorman s.d.) -, que geralmente está associada a criação do kuduro e onde, atualmente, são encontrados seus grandes centros produtores.

Sebém e Tony Amado são figuras fundamentais do gênero (Moorman s.d.), pois personificam essas narrativas de fundação, tanto no imaginário popular quanto em seus discursos. Como um dos jovens que teve a experiência de viver na Europa e frequentar os clubes do centro de Luanda nos quais fazia "animações" - ou seja, falava sobre as batidas de música eletrônica enquanto eram tocadas -, à Sebém é comumente creditado o modo como o kuduro era cantado a princípio. Ele se coloca como um dos principais difusores do gênero (informação oral) e é reconhecido por ter dado voz a uma de suas mais importantes músicas "A felicidade" (1989). Por sua vez, Tony Amado afirma ter se inspirado em uma cena em que Jean-Claude Van Damme dança no filme Kickboxer ${ }^{11}$ para criar a outra parte distintiva do gênero: seus movimentos corporais ou toques. Desde o início e ainda hoje a dança está intrinsecamente associada às músicas de kuduro, podendo algumas delas ser acompanhadas por passos específicos. Eles foram significativos para a geração do movimento musical que, segundo Amado, teria brotado dos musseques (informação oral). $\mathrm{O}$ artista também argumenta ser o responsável pela nominação que aquelas batidas vão ganhar posteriormente, pois, com suas coreografias e músicas como "Amba Kuduro" (1993/94), o nome do gênero teria se tornado popular. Embora não haja consenso, essa é uma história mencionada por pesquisadores do gênero (Moorman s.d. 2014, Alisch \& Siegert 2011, Sheridan 2013, Marcon 2016), contada repetidas vezes nos programas de televisão angolanos e também em vídeos disponíveis no canal do Youtube do músico e dançarino, nos quais ele tenta estabelecer a "verdade sobre a história do kuduro".

Para além dessas disputas e da suposta obviedade que a palavra kuduro poderia adquirir entre os falantes da língua portuguesa, a historiadora norte-americana Marissa Moorman (s.d. 2014) adota uma interessante perspectiva para a nomeação do gênero de música e dança. Nela, o termo se aproximaria do quimbundo, uma das línguas nacionais angolanas, na qual a partícula "cu" estaria associada a "lugar". Como consequência, seria estabelecida uma relação direta entre a expressão e as circunstâncias e a vida dura (e violenta) experienciada pelos angolanos. Nesse sentido, ela aponta ainda que o vocábulo já era corrente no país pelo menos desde os

11 Kickboxer. Direção: Mark Di Salle, David Worth. EUA, 1989. 
anos de 1970. Para as pesquisadoras Stefanie Alisch e Nadine Siegert (2013), essa violência e sofrimento são, de alguma forma, traduzidos no movimento dos corpos, no momento da dança. Um momento no qual seriam criados espaços - embora não conscientes -, para lidar com os horrores e traumas das sucessivas guerras, assuntos geralmente eclipsados em grande parte das letras que compõem o repertório do kuduro.

As discussões sobre as origens do kuduro são frequentes entre artistas e público (Moorman s.d.) e tomam lugar nos meios de comunicação angolanos assim como nas plataformas virtuais. ${ }^{12}$ Sebém e sua contraparte Tony Amado, ao criarem suas contendas, acabam por simbolizar as disputas, como também a complementaridade entre centro e musseque no imaginário que ronda a criação do kuduro. Ajudam ainda a alimentar as disputas ou beefs, tão característicos do gênero e que fazem crer que há pouca ou nenhuma harmonia entre os artistas. Cabe pontuar, entretanto, que as relações entre as duas partes da cidade (e seus membros) parecem ser mais fluidas do que as histórias que circundam a constituição do kuduro poderiam sugerir.

De qualquer forma, como já mencionado, o musseque tem sido considerado um lugar de grande potência e ebulição cultural, no qual música, dança, cotidiano, valorização dos aspectos locais e identidade nacional estão entrelaçados. Era ali, ainda no período de guerras, que as pessoas se juntavam em torno de reivindicações políticas e sociais, mas também do semba - gênero de música e dança mais tradicional. Ali eram também criados espaços culturalmente independentes em um contexto repleto de arbitrariedades (Moorman, s.d). Hoje, com movimentos culturais como o kuduro, esse legado parece continuar ao reafirmar a importância da música popular na constituição das identidades e da "angolanidade", ${ }^{13}$ o patriotismo cultural angolano (Moorman s.d., Alisch \& Siegert 2011, Sheridan 2013).

É comum a praticantes e estudiosos do kuduro compreendê-lo e narrá-lo a partir da ideia de gerações (Moorman s.d., Sheridan 2013). Essa interpretação enaltece os pioneiros do gênero, assim como enfatiza sua continuidade ao longo dos anos. De maneira semelhante, essa perspectiva evidencia algumas transformações técnicas e tecnológicas, rítmicas e sonoras, assim como culturais, estéticas e de conteúdo lírico pelas quais o gênero tem passado desde seu surgimento. Além disso, destaca a capacidade do kuduro e dos kuduristas de renovarem-se constantemente. Nesse sentido, Moorman (s.d.) argumenta:

A primeira geração [...] é tida como a criadora do gênero (embora as disputas continuem sobre o que aconteceu, quando, quem foi o primeiro e etc.). A música dessa geração é descrita como "música de animação" música para fazer as pessoas dançarem tipicamente superficial em termos de conteúdo, mas cheia de energia, de batidas vibrantes, música da qual "Estamos sempre a subir!" é um exemplo clássico. A segunda geração [...] desenvolveu o conteúdo e a batida da música acrescentando rimas e refrãos mais complexos e começou a produzir videoclipes. A terceira geração de artistas [...] oferece letras mais elaboradas, propõe desafios verbais com outros artistas [chamados "bifes"] e se identifica com bairros específicos de Luanda.

12 Há diversos vídeos, alguns de programas de televisão angolanos, outros produzidos pelo próprio Amado, nos quais tenta-se traçar as origens e os responsáveis pelo surgimento do kuduro. Neste artigo, é destacada a série de vídeos “Quem inventou o kuduro?”, de 2010, feitos a partir do programa de televisão Tchilar (TPA) e disponíveis em: https://www.youtube.com/watch?v=aQqfPu2XCjo. Parte da argumentação referente a Sebém foi retirada de uma entrevista realizada em outubro de 2013, momento em que o artista esteve no Rio de Janeiro, para o lançamento do filme I love kuduro: from Angola to the world, (Mário Patrocínio. Portugal/Angola 2013).

13 Em diálogo com o pensamento da historiadora norte-americana Marissa Moorman, as pesquisadoras alemãs Stefanie Alisch e Nadine Siegert (2011) argumentam que "a angolanidade fala dum sentimento de identidade, tanto enraizado em práticas culturais locais como no cosmopolitismo, sendo assim um 'cosmopolitismo enraizado' ou 'patriotismo cosmopolita". 
A identificação com as comunidades ou musseques onde vivem - muitas vezes o pano de fundo para seus videoclipes -, é fundamental para os kuduristas. São diversas as menções a eles, assim como as disputas em torno de quem seriam seus legítimos defensores e representantes. Esses elementos são reelaborados em algumas letras de suas músicas, assim, a título de exemplo, enquanto Nagrelha (autodenominado "Estado Maior do Kuduro") entoa "Sou nascido e crescido no gueto [...] Sambizanga, meu patrimônio, minha riqueza”, ${ }^{14}$ Bruno M, canta "Os Combatentes será sempre minha fortaleza urbana. A voz é o maior meio de expressão humana". ${ }^{15}$

As músicas têm o cotidiano como tema privilegiado e permitem que esses jovens ganhem destaque e ascensão como músicos, bailarinos, produtores e DJs dentro e para além das localidades onde residem. Alguns deles encontram neste meio caminhos que os afastam do anonimato e até mesmo da criminalidade. Essa é a opinião de artistas como Dog Murras ${ }^{16}$ e parece ter sido a trajetória de alguns músicos do gênero. Como aponta Moorman (2014: 37), "kudurista é agora uma categoria profissional em potencial, um caminho para o progresso individual tanto quanto um empenho criativo e artístico" (tradução minha).

Ainda que possa ser considerado um ambiente majoritariamente masculino, o kuduro abre espaço para que alteridades sejam reveladas, como no caso da transexual Titica. A despeito dos preconceitos existentes em um país no qual boa parte da população é cristã e onde outras formas de sexualidades podem ser consideradas ilegais, a cantora faz sucesso nos palcos nacionais e tem representado Angola em países da Europa, nos Estados Unidos e no Brasil, ${ }^{17}$ onde se apresentou no último Rock in Rio, a convite da banda BaianaSystem. No kuduro também cabe a inserção de outras sonoridades, como o afrohouse, e formas de cantar como o "kuduro lamento”, uma versão mais melódica da música cujo um dos expoentes é Rey Loy. Nele há ainda lugar para a inclusão, como aposta W. King, de elementos do reggae tanto no vestuário quanto nas canções. Essas e outras propostas enfatizam o dinamismo do kuduro e possivelmente favorecem o alargamento da ideia de gerações, pois novos artistas, assim como novas ideias surgem todo o tempo.

Kuduro e kuduristas não são, entretanto, uma unanimidade, pois há críticas quanto ao envolvimento do governo com os artistas do gênero, seus usos políticos, além de sua precoce ascensão como um gênero musical representativo da cultura nacional, em detrimento de expressões mais tradicionais (Moorman s.d.). ${ }^{18}$ Apesar disso, suas músicas e danças têm ocupado diversos espaços na sociedade angolana, estando presentes nas festas de rua, clubes, casas noturnas e comemorações da classe média do país (Sheridan 2013, Moorman s.d.). De modo semelhante, o kuduro faz parte da trilha sonora de telenovelas e tem forte presença nas rádios e redes de televisão, algumas delas dedicam canais e programas especializados no gênero, como o recente Be Kuduro, o Kuduro Vivo e o Sempre a subir. Este último, atualmente apresentado por Príncipe

14 Trecho da música "95 minutos de bloqueio" (2014), de Nagrelha.

15 Trecho da música "Dança da tropa" (2008), de Bruno M.

16 Em entrevista ao programa Sempre a subir (TPA2), exibido em dezembro de 2015 e disponível em: https:// www.youtube.com/watch?v=wNmrZ63-Lnw

17 Para mais informações sobre Titica consultar: http://www.bbc.com/news/world-africa-17628726

18 Sobre algumas das polêmicas que envolvem a questão da representatividade do kuduro e sua ascensão a símbolo nacional ver dois artigos originalmente publicados no periódico Semanário Angolense no ano de 2010: "Kuduro, o novo 'embaixador' da música angolana?" Disponível em: http://www.angonoticias.com/Artigos/ item/26819 e "Uma estranha obsessão oficial pelo kuduro", de Ismael Mateus no Semanário Angolense. Disponível em: http://rezervado.blogspot.com.br/2010/06/opiniao-uma-estranha-obsessao-oficial.html 
Ouro Negro e Presidente Gasolina, é exibido pelo menos desde 2009 pela Televisão Pública Angolana (TPA2) e pelo canal internacional da companhia. Por fim, também há lugar para ele em premiações como o Angolan Music Awards (AMA), que abriga categorias exclusivas para o gênero e em eventos como a Conferência Internacional do Kuduro ${ }^{19}$.

Fluido e plástico, ao longo de sua formação, a escuta e algumas práticas do kuduro não têm se limitado aos candongueiros - um tipo de transporte coletivo que atravessa as ruas de Luanda e no qual o gênero é trilha sonora; um espaço que serve como propaganda e indicador de possíveis sucessos (Alisch \& Siegert 2011, Tomás 2013, Moorman s.d.). Ele tem alcançado o mundo por meio da literatura premiada do escritor angolano Ondjaki, ${ }^{20}$ através de arquivos sonoros, sites de compartilhamento de música e vídeo, assim como pelos processos migratórios, especialmente aqueles que levam os angolanos em direção a Portugal (Marcon \& Tomás 2012). Nesse país, o kuduro ganhará novos sentidos com DJs como Marfox e grupos ou coletivos como Pupilos do Kuduro, Batida e o Buraka Som Sistema, com sua proposta de um "kuduro progressivo" (Alisch e Siegert 2011; Sheridan 2013; Moorman s.d.) e a promoção de festas conhecidas como Hard Ass Sessions. Além deles, há outros destaques como a banda Throes + The Shine, cujo primeiro trabalho (Rockuduro 2012) propunha uma mistura potente do gênero com o rock. A diversidade de grupos, estilos, rítmicas e estéticas sugere igualmente uma diversidade de identificações, pertenças, permanências, e intensidades de relações com o gênero.

Com coletivos como o Batida, a tomada do kuduro se oferece como uma oportunidade de reaproximação com a África (Alisch e Siegert 2011) e, além disso, como elemento de reflexão, crítica e revisão da história angolana e das promessas que não se cumpriram. ${ }^{21}$ Para bandas de alcance global, como o Buraka Som Sistema, o kuduro é ressignificado para tomar as pistas de dança (Sheridan 2013). Pode ser entendido como uma das referências formativas de seu vasto repertório musical; um repertório com o qual os integrantes conviveram desde cedo no bairro que dá nome ao grupo e complementado pela ampla variedade de sonoridades descobertas ao redor do mundo. ${ }^{22}$ Nesse sentido, cabe ressaltar que o Buraka tem também conexões com o funk brasileiro, sendo responsável por parcerias com artistas do gênero como Deise Tigrona e MC Bin Laden, convidado para participar, em Lisboa, da "Globaile", uma festa que reuniu diversos artistas e celebrou os dez anos da banda. $\mathrm{Na}$ mesma cidade, o gênero musical brasileiro está presente nas chamadas "discotecas africanas" - onde divide espaço com outro gêneros de música brasileiros e angolanos -, e em festas próprias, como a "I love baile funk" e a "Funk-se Europe". Ainda sobre os Buraka, vale mencionar que Blaya, cantora e bailarina de origem brasileira, a única integrante feminina do grupo, dedica-se também a dar aulas de dança que podem incluir além do próprio kuduro, o funk brasileiro.

19 A Kuduro International Conference, da qual tive a chance de participar ainda nos momentos iniciais da pesquisa, tomou lugar em Luanda, entre os dias 23 e 25 de maio de 2012 e reuniu, além de pesquisadores de diversas partes do mundo, músicos, dançarinos e produtores do gênero.

20 No livro Quantas madrugadas tem a noite (2010), Ondjaki conduz o leitor pelas ruas de Luanda através das peripécias de um narrador que ao contar as dificuldades em se fazer um enterro, apresenta aspectos da história e da cultura angolana, sendo o kuduro, uma das trilhas sonoras da aventura.

21 Nesse sentido, importa indicar que um dos membros do coletivo, Luaty Beirão, o Ikonoclasta, conhecido por suas fortes críticas ao governo angolano, estava entre os 17 ativistas presos e condenados à prisão, em 2015, sob a acusação de associação criminosa e preparação de rebelião.

22 Mas, não em nenhum lugar do mundo. No filme de nome sugestivo Off the beaten track (João Pedro Moreira. Portugal 2013), pode ser acompanhada a origem e a trajetória da banda, suas viagens de trabalho e pesquisa de novas sonoridades produzidas por artistas assentados em países como Angola e Venezuela. A versão curta do filme está disponível em: https://www.youtube.com/watch?v=u5vAINF-D5Q. 
Considerando ainda as (re)tomadas do kuduro fora de Angola, é necessário pontuar que Portugal tem, desde a década de 1970, recebido grande número de pessoas oriundas dos Países Africanos de Língua Oficial Portuguesa (PALOP), muitos deles levaram em suas bagagens as culturas dos lugares onde nasceram. $\mathrm{O}$ kuduro é um dos gêneros musicais que aos poucos despontam como referência nas regiões periféricas de Lisboa e algumas cidades de seu entorno. Assume, nessa conjuntura, um papel fundamental na socialização de imigrantes e jovens de descendência africana, estando presente nos encontros de família, escolas, festas e na internet, tornando-se parte constituinte das experiências cotidianas daquelas pessoas (Alisch e Siegert 2011, Marcon 2011, Marcon \& Tomás 2012, Sheridan 2013).

Distintas apropriações do gênero também são possíveis considerando-se os angolanos e africanos de outras nacionalidades, residentes em países europeus situados para além do contexto lusófono, como a França. Neste lugar são encontrados artistas que se identificam com o kuduro (Alisch e Siegert 2011), e casas noturnas nas quais - como indicou o jornal Libération ${ }^{23}$, em 2012 -, suas batidas fazem sucesso. É também na França que surge um dos primeiros projetos internacionais relacionados ao gênero, o Kuduro Sound System (2006), encabeçado pelo DJ Fréderic Galliano. Ele não é, entretanto, o único, pois ao longo dos anos, outros artistas e produtores musicais estrangeiros têm notado e salientado a potência e a inventividade do kuduro.

Identificando essas possibilidades de circulação e suas ressignificações Alisch e Siegert (2011) consideram três plataformas nas quais o gênero se faz presente: Luanda, Lisboa e o que denominam de "pistas de dança ao redor do mundo". Tais plataformas, espaços físicos, simbólicos e sociais carregam consigo distintas formas e práticas relacionadas ao gênero, assim como distintos discursos identitários e de pertencimento, sendo consideradas por seus produtores mais legítimas as manifestações quanto mais próximas de Angola (e seus musseques).

No Brasil, o kuduro, ou uma variante dele, ficou amplamente conhecido em 2012 em razão da abertura da telenovela Avenida Brasil. Entretanto, "Vem dançar com tudo", uma versão da música de sucesso internacional "Danza kuduro" (2010), assim como o enredo apresentado pela TV Globo, teve pouca ou nenhuma referência ao gênero de música produzido em Angola. Diferente do que aconteceu com outra novela, a angolana Windeck, cuja abertura era composta pela música de mesmo nome, popular em diversas regiões da África e interpretada por Cabo Snoop. A trama ambientada em Luanda foi transmitida em 2015 pela TV Brasil, que apresentou uma série de reportagens sobre os variados aspectos de Angola e disponibilizou em seu site um glossário com algumas expressões comuns no país, no qual estavam incluídos os termos kuduro e kudurista. Antes disso, porém, o carnaval de Salvador já havia agregado a sonoridade desse gênero aos blocos e trios elétricos, com artistas como Dog Murras, um dos principais nomes da música angolana, conhecido pelos usos intensivos que faz dos símbolos nacionais do país (Alisch \& Siegert 2011, Moorman s.d., Marcon 2016). Outra breve inserção do gênero nos meios de comunicação brasileiros se deu em 2009, ano em que a TV Record promoveu um concurso de dança kuduro, cujo vencedor ganharia a oportunidade de conhecer Angola.

Ainda que haja uma percepção de que as formas de kuduro produzidas fora do país possam, de algum modo, publicizar a cultura, a música e os artistas angolanos, produtores locais

23 A edição online está disponível em: http://next.liberation.fr/musique/2012/10/09/le-kuduro-saga-dandy-noire_852092. 
como Príncipe Ouro Negro e Presidente Gasolina ${ }^{24}$ - famosos pela criação de uma linguagem própria -, apontam diferenças significativas entre o que é criado por eles e alguns músicos estrangeiros. A quantidade de batidas por minuto (entre 130 e $140 \mathrm{BPM}$ ), uma das características distintivas do gênero e responsável por instigar a agressividade do canto, é geralmente um fator de discrepância; por essa razão, os kuduristas angolanos tendem a achar que as músicas criadas por artistas internacionais são mais lentas que as suas. Nesse contexto, a legitimidade e a verdade de quem o produz localmente (e no "gueto") são constantemente reafirmadas, pois conforme apontou Lil Pasta Sacerdote do Kuduro, "para ser kudurista tem que beber o kuduro, viver como kudurista, falar como kudurista, andar como kudurista". ${ }^{25}$ Ao defender esses argumentos, ele aponta para aspectos singulares do movimento. Elementos de diferenciação tais como vivência, vestuário e fala são considerados atributos importantes e servem, ao mesmo tempo, como distinção dos kuduristas enquanto um grupo específico, assim como ponto de partida para que os artistas se destaquem individualmente e exerçam suas rivalidades.

Sentindo a necessidade de evidenciar a origem angolana do kuduro e relacioná-lo de forma mais estreita à história e à cultura do país, surgem nesse contexto de disputa, propostas como as do projeto Os Kuduristas, que assumem o papel de fazer com que o gênero seja mundialmente conhecido. Encabeçado pelo produtor cultural e músico Coreon Dú e sua produtora Da Banda - também responsáveis por iniciativas como o festival de música I Love Kuduro e o filme I love kuduro: from Angola to the world -, este empreendimento levou, entre 2012 e 2013, para países como Estados Unidos, Holanda, França, Alemanha e Brasil, elementos da cultura angolana, tendo como destaques a música e a dança kuduro.

Analisando projetos como esses, António Tomás (2013) e Marissa Moorman (2014) indicam existir em tais investidas uma tentativa de reorientação, de reformulação (rebranding) do kuduro, de modo que suas imagens substituam as percepções negativas que se tem do país e, ademais, com o intuito de torná-lo uma marca (original e rentável) de Angola. Tomás vai adiante, entretanto, ao pontuar que as aproximações entre setores do Estado angolano e o kuduro exercem a função de agregar à estrutura estatal uma manifestação cultural nascida às suas margens, e que por isso poderia escapar do controle das instituições oficiais, acostumadas a patrocinar músicos e artistas ainda nos tempos de guerra (Moorman s.d., Marcon \& Tomás 2012). Nesse sentido, cabe assinalar o fato de Coréon $\mathrm{Dú}^{26}$ ser filho do ex-presidente angolano José Eduardo dos Santos, o que se por um lado insinua uma possibilidade de legitimação e retomada do gênero por parte de iniciativas nacionais, por outro, engendra questionamentos quanto a apropriações e aproximações entre manifestações culturais juvenis e política, sobretudo em um contexto de permanentes tensões.

24 Entrevista realizada em outubro de 2013, momento em que os artistas estiveram no Brasil para o lançamento do filme I love kuduro: from Angola to the world, de Mário Patrocínio.

25 Entrevista feita via Facebook, entre os dias 15 e 18 de maio de 2017.

26 Ao indicarem a retomada do kuduro como uma estratégia para a criação de imagens positivas de Angola, Tomás (2013) e Moorman (2014) apontam que Coreon Dú, assim como sua irmã, Tchizé dos Santos foram responsáveis pela produção de conteúdo e efetivação da parte de entretenimento da Televisão Pública de Angola, TPA2, por meio de empresas como a Semba Comunicação. Mais informações sobre a Semba Comunicação e seus produtos, alguns deles, mencionados neste artigo, podem ser encontradas no site da companhia http://www. semba-c.com/pages/view/35/semba-comunicacao. Além disso, em entrevista dada por Tchizé dos Santos ao programa Hora Quente (TPA2), ela relata seu papel na concepção da TPA2 e da TPA Internacional https://www. youtube.com/watch?v=hMDjDJr5kBA. 


\section{Conclusões: O funk brasileiro e o kuduro angolano entre O local e o global}

Se a globalização enquanto conceito ainda parece um tanto difusa, e a ideia dos fluxos e trocas culturais pouco palpável, essa impressão seria alterada no momento em que esses fenômenos deixam ser imaginados como se estivessem para além dos indivíduos que, deste modo, são capazes de agregá-los a seus contextos e transformá-los conforme desejam. Se nossa sociedade for entendida como uma complexa trama de grupos identitários, práticas e códigos culturais que não se excluem, mas, ao contrário, estão em profundo diálogo e elaboração criando cotidianamente processos de construção de alteridades e identidades, esse cenário também se modifica. Além disso, com a possibilidade de deslocamento da produção de identidades para outras instâncias, seriam abertos novos espaços formativos e modos mais fragmentados e fluidos de constituição dos sujeitos e de suas práticas permitindo a identificação e o acesso a identidades múltiplas, diversas e até mesmo contraditórias (Hall 1998).

Este artigo teve o propósito de indicar como os protagonismos juvenis manifestos por meio das expressões musicais têm se beneficiado bastante deste momento. Se separadamente, funk brasileiro e kuduro angolano possuem suas peculiaridades, considerados juntos, evidenciam a tendência, na qual periferia, globalidade, identidade, cotidiano, corporeidade e tecnologia se articulam por meio da música (e das imagens produzidas a partir dela). Um e outro são geridos, portanto, em um contexto no qual a constituição das identidades ocorre de maneiras cada vez mais fluidas, podendo - assim como a adesão a manifestações culturais -, transcender a localidade e encontrar caminhos e intersecções para além das fronteiras físicas e simbólicas da vizinhança, da cidade e do país de origem.

Essas transformações seriam, deste modo, capazes de engendrar novos modos de produção e construção dos sujeitos, cujas constituições não dependeriam apenas de instituições tradicionais ou formais (Dayrell 2002, Marcon \&Tomás 2012). Nesse sentido, Dayrell (1999: 27) sugere que "a música é uma dimensão presente na história cultural da humanidade, acompanhando as transformações do homem e da sociedade, expressando, de alguma forma, nas melodias e nas letras, a relação do indivíduo com o seu mundo, no seu tempo". A globalização é parte desse processo, e a música, por sua plasticidade, componente de análise privilegiado nessa conjuntura (Taylor 1997).

Jovens funkeiros e kuduristas estão conectados com o mundo através da rede mundial de computadores, onde podem ser instituídos espaços alternativos de socialização e criação coletiva. São empoderados pelo desenvolvimento e o barateamento de aparatos tecnológicos que permitem que seus gestos, criações musicais e visuais, saiam "do quarto para a rua (e o mundo)"27; criam alternativas de produção, divulgação e consumo que nem sempre passam pelo aval ou conhecimento de grandes gravadoras e meios de comunicação tradicionais (Marcon \& Tomás 2012, Vianna 2013). Servem-se de um momento singular no qual as culturas marginalizadas ganham destaque, e conquistam espaços de representação nos quais criam narrativas próprias, muitas vezes divergentes daquelas comumente contadas (Dayrell 2002; Aderaldo e Raposo 2016).

Funk e kuduro emergem e se estabelecem numa conjuntura de violência e segregação, falta de infraestrutura e oportunidades. São criados majoritariamente em zonas urbanas degradadas

27 Em referência ao projeto do DJ angolano Satélite. 
e enclaves sociais, favelas, comunidades, periferias, musseques de grandes cidades, mas, apesar disso, seus produtores não se inibem. Ostentam seus desejos, criam imaginários de abundância, consumo e poder (Marcon \& Tomás 2012, Pereira 2014). Em estúdios caseiros pouco equipados, distantes das grandes gravadoras e com auxílio das plataformas digitais (Sá 2007, Alisch e Siegert 2011, Marcon \& Tomás 2012), acabam por instituir musicalidades sui generis, variedades de "músicas eletrônicas populares" (Sá 2007) que formam com outros gêneros ao redor do mundo uma espécie de "rede global periférica" (Pereira 2014); uma rede produzida por meio de contínuas combinações das referências locais e globais, mas que também é capaz de devolver ao mundo uma inventividade que se destaca dentro e fora dos países onde são geradas.

A valorização dos ambientes onde vivem, demonstrada a partir das letras de músicas e dos nomes artísticos que escolhem é outra característica compartilhada entre funkeiros e kuduristas. Isso não impede, como já indicado, que haja um profícuo diálogo dessas expressões culturais com gêneros e estéticas estabelecidos pelo mundo. Embora não explorados nos limites deste artigo de maneira mais sistemática ou crítica, é importante ressaltar que diversos autores - entre eles Robertson (1994), Taylor (1997) Agier (2001), Hannerz (1999), Hall (2006), Canclini (2007) -, desenvolveram ideias e termos (glocalização, hibridização, crioulização) para pensar o encadeamento do global sobre as culturas locais e suas possibilidades de interação. Muitos deles - sem desconsiderar as implicações políticas, sociais e econômicas -, tentaram superar análises consideradas reducionistas e nas quais as palavras globalização e homogeneização são tratadas como sinônimos, para pensar os processos culturais a partir da chave da transformação. Nesse sentido, como indicam Aderaldo e Raposo (2016) para o caso dos coletivos de rappers em Portugal, a relação entre elementos locais e globais não implica desconexão com o local, diferente disso, esses gêneros (e aqueles envolvidos neles), parecem estar mais interessados nas possibilidades de intersecção e mistura que na oposição entre eles. Assim, referentes estrangeiros e locais são valorizados e recombinados (Sá 2007, Alisch \& Siegert 2011, Tomás 2013). No funk, o próprio nome já indica essa influência. Além disso, sonoridades afro-brasileiras, temas cotidianos das comunidades e imaginários internacionais, como os do hip hop norte-americano, fazem parte das contínuas misturas do gênero brasileiro. No kuduro, a "influência diaspórica” (Moorman s.d.) do hip hop na dança, por exemplo, também tem seu lugar (Alisch \& Siegert 2011, Tomás 2013), assim como expressões musicais nacionais, música eletrônica, afrohouse e até mesmo o reggae.

Provocando e se valendo de mudanças que impactaram de modo direto a produção, divulgação e o consumo de música (barateamento dos equipamentos, popularização de plataformas de divulgação de música e vídeo), funk e kuduro se inscrevem, portanto, como dois gêneros musicais mediados pela tecnologia (Marcon \& Tomás 2012, Pereira 2014, Vianna 2013). Porém, se por um lado ela nem sempre está isenta de interesses e o acesso a ela possa se dar de formas variáveis, por outro, viabiliza que esses jovens imaginem (Pereira 2014), protagonizem e narrem suas próprias histórias por meio de músicas e imagens. Isso, de certa maneira, dá visibilidade a manifestações culturais que, de outro modo, poderiam ser pouco valorizadas. Além disso, o autodidatismo no uso de recursos tecnológicos e comunicacionais gera outros tipos de relação com a indústria da música (Dayrell 2002; Marcon \& Tomás 2012), pois funkeiros e kuduristas não dependem apenas dela para serem reconhecidos e podem se corresponder de modos mais diretos com seus ouvintes e interlocutores, estejam eles próximos ou distantes. Como afirmam Marcon \& Tomás (2012: 138-139) para o kuduro, mas, identicamente significativo, para o caso do funk, 
Boa parte destas transformações está relacionada ao advento de novas tecnologias para a comunicação e os novos formatos de acesso ao consumo cultural. De um lado a individualização dos computadores e dos dispositivos de áudio, vídeo e informação e de outro a internet e a telefonia móvel se tornaram extremamente populares e comuns a toda uma geração de crianças, adolescentes e jovens que passaram a dominar estas ferramentas e o funcionamento destes novos mecanismos de expressão desde antes de sua alfabetização, embora com intensidade desigual, a depender das condições socioeconômicas e culturais, bem como dos contextos políticos em que vivem.

Alguns aparatos tecnológicos (softwares e sites criação e compartilhamento de música e vídeo, a título de exemplo), são bastante hábeis em se apresentar como uma alternativa para essas e outras expressões musicais em um contexto aparentemente mais democrático. Abre-se, desta forma, um campo de possibilidades com relação à circulação no cenário global por meio da migração e/ou dos fluxos físicos, virtuais e internacionais de cultura. Isso acaba por preencher o imaginário de alguns produtores de funk e kuduro, sendo possível encontrar em seus trabalhos (mesmo entre os mais famosos), frases e slogans que apontam para os desejos de que as trajetórias pessoais e musicais articulem-se local e globalmente, ou seja, da periferia para o mundo. Aspirações e desejos revelados em expressões como "Do circuito fechado para o mundo", do MC angolano Sacerdote e "Da favela para o mundo", da funkeira Valeska Popozuda. Essas possibilidades se tornam viáveis e ganham importância considerada a visibilidade alcançada por esses gêneros e seus artistas nos últimos anos, a despeito da posição que alguns deles ocupa na grande indústria da música e até mesmo nas sociedades das quais fazem parte.

Embora os espaços abertos pelas novas tecnologias tenham ampliado a produção e o acesso a esses e outros tipos de música, quando ponderamos sobre a periferia também consideramos a relação que os gêneros de música têm com as indústrias discográfica e da cultura (Robinson,1991). Funk e kuduro nem sempre são parte delas, entretanto, esta relação não é determinada e pode variar, visto que apesar de terem sido criados de forma mais autônoma, por vezes seus adeptos estão em diálogo, mesmo que transitório, com elas. É o caso do kuduro que tem despontado como símbolo nacional (Marcon \& Tomás 2012, Moorman s.d.), mas também do funk que, apesar de não possuir tal condição, permeia de forma cada vez mais intensa os meios de comunicação brasileiros e tem ídolos ligados a gravadoras estabelecidas. Como aponta Sotero Caio (2013: 2), "as estéticas periféricas se revelam estratégicas e astutas, uma vez que desvendam profundas nuances mercadológicas numa dialética de resistência e integração”. Funk brasileiro e kuduro angolano podem ainda, ser considerados dentro de um contexto mais amplo no qual as sonoridades produzidas nas periferias despontam como um grande celeiro criativo no qual produtores estrangeiros buscam estéticas musicais originais que ajudam a divulgar ao redor do mundo. ${ }^{28}$ Apesar das críticas e implicações que tais "descobertas" suscitam, músicos como M.I.A., Diplo e Daniel Haaksman, são alguns nomes mais mencionados quando esse interesse estrangeiro é colocado em questão.

Para além dessa dimensão que torna realizável uma criação mais global e justaposta das identidades, o funk brasileiro e o kuduro angolano têm um importante papel na valorização dos lugares onde são majoritariamente criados, cantados e dançados. Apesar das dificuldades, demonstram que esses espaços estão repletos de cultura e protagonismos. Capazes de produzir ídolos, tendências, inovações estéticas, gestuais, visuais e sonoras. Considerados por alguns produtores (Grandmaster Raphael e Coren Dú) e pesquisadores (Sá 2007, Wilper 2011) os primeiros tipos de música eletrônica produzidos em seus respectivos países, funk e kuduro, ao

28 Para mais informações sobre alguns desses "mediadores", consultar: Rocha, Camilo. "Globalistas' buscam sons periféricos". In: http://www1.folha.uol.com.br/folha/ilustrada/ult90u358180.shtml 
alcançar tais possibilidades de ação provocam, a seu modo, pequenas revoluções que de alguma forma tornam discutíveis acusações que lhes são feitas quanto à falta de reivindicações explícitas por parte de seus produtores.

Seja como forma de diversão, trabalho ou estilo de vida, funk e kuduro persistem criando modos e lugares alternativos de produção de cultura e identidades, novos espaços de fala e atuação. Nos lugares onde vivem e transitam, seus artistas encontram inspiração e seu público mais fiel. Isso não torna suas práticas, músicas, anseios e imaginários enraizados, sobretudo em um contexto no qual a imaginação parece ultrapassar espaços físicos e simbólicos, articulando, deste modo, local e global.

\section{REFERÊNCIAS BIBLIOGRÁFICAS}

Aderaldo, Guilhermo, \& Raposo, Otávio. 2016. Deslocando fronteiras: notas sobre intervenções estéticas, economia cultural e mobilidade juvenil em áreas periféricas de São Paulo e Lisboa. Horizontes Antropológicos, 22(45), 279-305.

Agier, Michel. 2001. "Distúrbios identitários em tempos de globalização. Mana, vol. 7 n. 2.

Alisch, Stefanie e Sierget, Nadine. 2011. “Angolanidade revisited”. Disponível em: http://www. buala.org/pt/palcos/angolanidade-revisited-kuduro. Última consulta em 11/2017.

. 2013. "Dancing war trauma in Angolan kuduro. In: Bisschof, Lizelle.; Van Peer Stefanie. Art and trauma in Africa: Representation of reconciliantion in music, visual arts, literature and film. New York. Ibitarius.

Appadurai, Arjun. 1996. Modernity at large: Cultural dimensions of globalization. University of Minnesota Press.

Arruda, Angela, Jamur, Marilena, Melicio, Thiago, \& Barroso, Felipe. 2010. "De pivete a funqueiro: genealogia de uma alteridade”. Cadernos de Pesquisa, 40 (140), 407-425.

Assef, Cláudia. 2003. Todo DJ já sambou: a bistória do disc-jóquei no Brasil. São Paulo: Conrad Editora do Brasil.

Caio, Manoel Sotero. 2013. "Cumbia villera, Kuduro e Technobrega: repercussões e repertórios dinâmicos das cenas musicais". Trabalho apresentado no XXIV Congresso da Associação Latinoamericana de Sociologia. Santiago, Chile. Disponível em: http://actacientifica.servicioit.cl/biblioteca/gt/GT3/GT3_CaioNetto.pdf

Canclini, Néstor. 2007. A globalização imaginada. São Paulo: Iluminuras.

Dayrell, Juarez. 1999. 'Juventude, grupos de estilo e identidade”. Belo Horizonte: Educação em revista, pp. 25-39.

. 2002. "O rap e o funk na socialização da juventude". 2002. Educação e Pesquisa, São Paulo, v.28, n.1, p. 117-136.

Essinger, Silvio. 2005. Batidão: uma história do funk. Rio de Janeiro: Record.

Faria, Debora C. 2014. “O local e o global no funk brasileiro e no kuduro angolano”. Dissertação de mestrado. Guarulhos: Escola de Filosofia, Letras e Ciências Humanas, Universidade Federal de São Paulo.

2015. "Da favela para o mundo: articulações entre o local e o global no funk brasileiro". Brasiliana - Journal for Brazilian Studies, 4(1), 55-81.

Freire, João E Herschmann, Micael. (2003) "Funk carioca: entre a condenação e a aclamação na mídia”. Revista Eco-Pós. http://revistas.ufrj.br/index.php/eco_pos/article/view/1133. 
Hall, Stuart. 1998. A questão da identidade cultural. Textos didáticos. São Paulo, SP: IFHC/ Unicamp. 2006. A identidade cultural na pós-modernidade. Rio de Janeiro: DP\&A Editora.

Hannerz, Ulf. 1996. The local and the global: continuity and change. In: Transnational connections. New York/London: Routledge.

Herschmann, Micael. 2000. O funk e o hip hop invadem a cena. Rio de Janeiro: Editora UFRJ.

Marcon, Frank; Tomás, Cláudio. 2012. "Kuduro, juventude e estilo de vida: estética da diferença e cenário de escassez”. Tomo (UFS), pp. 137-167.

Marcon, Frank; Santos, Ely Dayse. 2016. "Música de festa, expressão de identidades, de estética e de poder na diáspora africana”. Trabalho apresentado na 30a Reunião Brasileira de Antropologia. João Pessoa, PB, Brasil.

Moorman, Marissa. S.d. "Sempre a subir!": música e dança kuduro na Angola pós-colonial. Trabalho apresentado nos Encontros Culturais da Língua Portuguesa. Rio de Janeiro, RJ, Brasil.

.2014. Anatomy of Kuduro: Articulating the Angolan Body Politic after the War. In: Afr. stud. rev. 57 (03), S. 21-40.

Ondjaki. 2010. Quantas madrugadas tem a noite. São Paulo: Leya.

Pereira, Alexandre Barbosa (2014). "Funk ostentação em São Paulo: Imaginação, Consumo e novas tecnologias da informação e da comunicação". Revista de Estudos Culturais, v. 1, p. $1-18$.

Robertson, Roland. 1994. "Globalisation or glocalisation?" Journal of International Communication, 1:1.33-52.

Robinson, Deanna Campbell [et al.] 1991. Music at margins: popular music and global cultural diversity. London: Sage Publications.

Sá, Simone. 2007. "Funk carioca: música eletrônica popular brasileira?!". Revista E-Compós. Brasília, DF, Brasil. Disponível em: http://www.compos.org.br/seer/index.php/e-compos/ article/view/195/196

Sheridan, Garth. 2013. "Luanda and Lisbon: Kuduro and Muscking in the diaspora In: Martins, R., M. de Barros, et al., Eds. Hispano-Lusophone Community Media:identity, cultural politics, difference. Herefordshire, Sean Kingston Publishing.

Silva, Luciane Soares. 2014. "Agora abaixe o som: UPPs, ordem e música na cidade do Rio de Janeiro”. Cadernos CHR, Salvador, v. 27, n.70, p. 165-179.

2016. "Baile Funk, missão civilizatória e UPP: cultura e segurança pública na cidade

do Rio de Janeiro". Brasiliana Journal for Brazilian Studies, [S.1.], v. 4, n. 2, pp. 318-342.

Disponível em: https://tidsskrift.dk/bras/article/view/22261/20554

Taylor, Timothy. 1997. Globalpop: world music, world markets. London and New York: Routledge.

Tomás, António. 2013. "Harnessing the energia of kuduro and its infrastructure of circulation".

Trabalho apresentado no Makerere Institute of Social Research. Uganda.

Vianna, Hermano. 1987. "O baile funk carioca: festas e estilos de vida metropolitanos".

Dissertação de mestrado. Rio de Janeiro: Museu Nacional, Universidade Federal do Rio de Janeiro.

. 2013. "O abacaxi da cultura” O Estado de São Paulo. Disponível em: http://www.estadao. com.br/noticias/impresso,o-abacaxi-da-cultura,995433,0.html

Wilper, Agnela Barros. 2011. "Kuduro de angola - A exclusão de uma nova linguagem". Trabalho apresentado no XI Congresso Luso Afro Brasileiro. Salvador, BA, Brasil. 


\section{CONTEMPORARY MUSICAL NARRATIVES BETWEEN THE LOCAL AND THE GLOBAL: THE cases of Brazillan funk and Angolan kUduro}

This article aims to understand the trajectory of two musical genres, Brazilian funk and Angolan kuduro. Despite their historical settings, funk and kuduro share some similarities. They are created, mainly, by young people living in marginalized areas of large cities, but although the prejudices and difficulties they face, they are connected with the world, especially through the global flow of people, sounds and images. These youngsters are empowered by how cheap and accessible technological artifacts have become and for that reason, they challenge the logic and dynamics of the cultural and entertainment industries by creating their own narratives and identities through the production of songs, body expressions and images. In this way, they challenge the role conferred on them as mere recipients to become protagonists and agents in and from the localities where they live, thus establishing new geographies of production, edition and consumption of music.

Keywords: Brazilian funk, Angolan kuduro, music, dance

Recebido em: 2017-06-12

Aceitado em: 2018-04-18 